\title{
Efficient In Vitro Labeling Rabbit Bone Marrow- Derived Mesenchymal Stem Cells with SPIO and Differentiating into Neural-Like Cells
}

\author{
Ruiping Zhang*, Jing $\mathrm{Li}^{1}$, Jianding $\mathrm{Li}$, and Jun $\mathrm{Xie}^{2}$
}

\begin{abstract}
Mesenchymal stem cells (MSCs) can differentiate into neural cells to treat nervous system diseases. Magnetic resonance is an ideal means for cell tracking through labeling cells with superparamagnetic iron oxide (SPIO). However, no studies have described the neural differentiation ability of SPIO-labeled MSCs, which is the foundation for cell therapy and cell tracking in vivo. Our results showed that bone marrow-derived mesenchymal stem cells (BM-MSCs) labeled in vitro with SPIO can be induced into neural-like cells without affecting the viability and labeling efficiency. The cellular uptake of SPIO was maintained after labeled BMMSCs differentiated into neural-like cells, which were the basis for transplanted cells that can be dynamically and non-invasively tracked in vivo by MRI. Moreover, the SPIOlabeled induced neural-like cells showed neural cell morphology and expressed related markers such as NSE, MAP2. Furthermore, whole-cell patch clamp recording demonstrated that these neural-like cells exhibited electrophysiological properties of neurons. More importantly, there was no significant difference in the cellular viability and $\left[\mathrm{Ca}^{2+}\right] \mathrm{i}$ between the induced labeled and unlabeled neural-like cells. In this study, we show for the first time that SPIO-labeled MSCs retained their differentiation capacity and could differentiate into neural-like cells with high cell viability and a good cellular state in vitro.
\end{abstract}

\section{INTRODUCTION}

Mesenchymal stem cell (MSC) transplantation is one promising approach to treat various central nervous system (CNS) diseases,

Department of Radiology, First Hospital,Shanxi Medical University, Taiyuan 030001, Shanxi, China, ${ }^{1}$ State Key Laboratory of Molecular Developmental Biology, Institute of Genetics and Developmental Biology, Chinese Academy of Sciences,Beijing 100101, China, ${ }^{2}$ Department of Molecular Biology, Shanxi Medical University, Taiyuan 030001, Shanxi, China

*Correspondence: zrp_7142@163.com

Received 20 January, 2014; revised 7 August, 2014; accepted 11 August, 2014; published online 18 September, 2014

Keywords: bone marrow-derived mesenchymal stem cells (BM-MSCs), differentiation, neural-like cells, superparamagnetic iron oxide (SPIO) such as spinal cord injury (Eftekharpour et al., 2008), stroke (Gutiérrez-Fernández et al., 2013), and neurodegenerative diseases (Joyce et al., 2010). Many studies based on animal experiments have demonstrated that MSCs can produce cytokines or growth factors that could lead to neural cell rescue and promote regeneration throughneuroprotection (Hsieh et al., 2013) or that they can differentiate into neural stem cells and ultimately develop into neural cells (Wang et al., 2013) and replace a lost population of cells to promote regeneration in vivo. Accordingly, MSCs and MSC-derived neural cells are considered to be ideal seed cells for replacement therapy in nervous system disorders due to the advantages of a plentiful source of cells, low immunogenicity, and fewer ethical concerns during autotransplantation applications (Harris et al., 2012; Van Velthoven et al., 2013).

To evaluate the safety and efficacy of stem cell-based therapy, there is a need for suitable imaging techniques that can ideally monitor the global cellular distribution, migration, differentiation, and homing of transplanted cells in vivo. Moreover, the fates of transplanted cells within the host should be effective and specific as well as non-invasive and non-toxic, especially in clinical medicine patients who require non-invasive techniques that can repeatedly monitor the tissue biodistribution of these cells.

For these points, cell labeling with contrast agents for magnetic resonance (MR) imaging provides the ability to monitor the in vivo behavior of the transplanted MSCs non-invasively. Previously, MR imaging has been successfully used to localize stem cells and to track their persistence and migration over time in animal models of stroke (Lu et al., 2013), injury (Li et al., 2013), degenerative diseases (Moraes et al., 2012) of CNS. Peldschusl (Peldschus et al., 2007) detected single superparamagnetic iron oxide nanoparticle(SPIO)-labeled MSCs using 3-T MR and proposed that the quantitative analysis of labeled stem cells was feasible. MR is an ideal means of detecting and tracking stem cells (Reddy et al., 2010). Resovist is a class of dextran-coated SPIO nanoparticles that has been approved by the Food and Drug Administration (FDA) as a MR imaging contrast agent. Previous studies have shown that transplanted MSCs and NSCs (Daadi et al., 2013) labeled with SPIO can be detected by MR imaging.

However, no studies have described whether SPIO-labeled MSCs could differentiate into neural-like cells, which is the basis for the treatment and tracking of SPIO-labeled MSCs in vivo.

In this study, BM-MSCs were labeled with SPIO and induced into neural-like cells. Moreover, the effect of labeling on the cellular viability, proliferation, and differentiation was determined. The 
results of this research may provide useful evidence for the future clinical application of SPIO-labeled MSCs for the treatment of nervous system disorders.

\section{MATERIALS AND METHODS}

\section{Animals}

Two healthy New Zealand white rabbits were purchased from the animal experiment center of our university and housed in a standard animal facility with 12-h on/off light conditions, and they were allowed standard food and water ad libitum. The rabbits were aged 2 months and weighed $600-700 \mathrm{~g}$. All procedures were approved by the Institutional Animal Care and Use Committee at our institution.

Isolation, induction, and identification of BM-MSCs

Approximately 1-3 $\mathrm{ml}$ bone marrow was obtained from each rabbit by puncture of the spinailiaca posterior superior thighbone under sterile conditions after being anesthetized by an intravenous injection of $3 \%$ pentobarbital sodium $(30 \mathrm{mg} / \mathrm{kg}$ ). Details of the isolation, induction, and identification of BM-MSCs are provided as supplementary data.

Cellular labeling and neural-like cell induction

Rabbit BM-MSCs were obtained according to the previous methods. The basic medium was DMEM supplemented with $10 \%$ fetal bovine serum (FBS). Passage 3 BM-MSCs were cultured in basic medium supplemented with Resovist containing 25 $\mu \mathrm{g} / \mathrm{mlsuperpara}$ magnetic iron oxide nanoparticle (Schering Co., Ltd., Germany) at $37^{\circ} \mathrm{C}$, in $5 \% \mathrm{CO}_{2}$ and saturated humidity for $24 \mathrm{~h}$ (Jing et al., 2008).

For neural-like cell differentiation, the SPIO-labeled BM-MSCs were pre-induced with $1 \mathrm{mmol} / \mathrm{L} \beta$-mercaptoethanol for $24 \mathrm{~h}$, washed three times with PBS, and cultured with DMEM supplemented with $40 \mathrm{ng} / \mathrm{ml}$ basic fibroblast growth factor (bFGF) for another $24 \mathrm{~h}$ (Suzuki et al., 2004), the cells were subjected to immunocytochemical analyses. To acquire the functional neurallike cells, the cells were then incubated in the presence of 100 $\mathrm{ng} / \mathrm{ml} \mathrm{bFGF}$ and over the next seven days, the cells were subjected to electrophysiological analyses (Janget al., 2010).

\section{Validation of labeling}

After incubation with SPIO, Prussian blue staining was used to detect iron within the cell cultures. This process induces a reduction of the ferric iron to the ferrous state with the formation of a blue precipitate. SPIO-labeled cells were washed twice with DHank's solution and fixed in 4\% paraformaldehyde for $10 \mathrm{~min}$. After washing with distilled water, the cells were incubated for 30 min with $2 \%$ potassium ferrocyanide in $2 \%$ hydrochloric acid, and the cells were incubated for $10 \mathrm{~min}$ by $0.5 \%$ neutral red. The labeling efficiency was determined by the manual counting of Prussian blue-stained cells.

RNA isolation and quantitative real-timepolymerase chain reaction

Total RNA was extracted using TRIZOL (Invitrogen) according to the manufacturer's instructions. Two micrograms of total RNA from each sample were reverse transcribed using M-MLV (Takara) in a final volume of $30 \mu \mathrm{l}$. The polymerase chain reaction (PCR) amplification was carried out using the IQ5 System (Bio-Rad) with SYBR Green Mastermix (Takara). All quantitative RT-PCR tests were carried out in duplicate and normalized to $\beta$ actin. The primer sequences used for qRT-PCR are listed in Supplementary Table S1.
Immunocytochemistry

The cultured cells were fixed for $10 \mathrm{~min}$ at $4^{\circ} \mathrm{C}$ in ice cold methanol, washed several times in phosphate-buffered saline (PBS), blocked in $3 \% \mathrm{H}_{2} \mathrm{O}_{2}$ for $30 \mathrm{~min}$ at room temperature, and then blocked for $30 \mathrm{~min}$ in $4 \%$ normal goat serum in $0.1 \mathrm{M}$ PBS with $1 \%$ PVP, $1 \%$ BSA, and $0.3 \%$ Triton X-100. The primary antibodies (NSE, MAP-2) were incubated overnight at $4^{\circ} \mathrm{C}$, washed with PBS, and then incubated with the secondary antibodies at room temperature for $20 \mathrm{~min}$. The incubated cells were washed in PBS, and DABC was incubated for $30 \mathrm{~min}$ at temperature. The cells were incubated in the $\mathrm{DAB} / \mathrm{H}_{2} \mathrm{O}_{2}$ solution for approximately 10 minutes and were then checked under a microscope for an optimal signal-to-noise ratio.

\section{Electrophysiological detection}

SPIO labeled BM-MSCs and SPIO labeled induced cells with neural-like morphology were chosen for whole-cell patch clamp recording. Plastic cover slips (Nunc) containing a monolayer cells were transferred to a recording chamber on the stage of an inverted microscope. The culture medium was replaced with extracellular solution containing: $140 \mathrm{mMNaCl}, 5 \mathrm{mMKCl}, 1 \mathrm{mM} \mathrm{CaCl}_{2}, 1$ $\mathrm{mM} \mathrm{MgCl}$, $10 \mathrm{mM}$ glucose, $10 \mathrm{mM}$ HEPES $(\mathrm{pH}=7.3)$; pipettes were filled with an intracellular-like solution containing $140 \mathrm{mMKCl}$, $5 \mathrm{mMNaCl}, 1 \mathrm{mM} \mathrm{CaCl}$, $10 \mathrm{mM}$ HEPES, $5 \mathrm{mM}$ EGTA, $2 \mathrm{mM} \mathrm{Mg-}$ ATP. The resistant of fire-polished pipettes was 5-10 M . All experiments were performed at room temperature. Ionic currents were recorded using the patch-clamp whole-cell configuration with Axopatch-200Bamplifier (AxonInstruments,USA)and digitized using a digidata 1322A A/D converter. Data were analyzed using pClamp10.1 and Originpro 8.0 software.

Assessment of cell viability

Calcein-AM/PI staining was used to evaluate the viability of labeled neural-like cells, and the cells were observed by confocal microscope (excitation $490 \mathrm{~nm}$, emission $617 \mathrm{~nm}$ ). The unlabeled and labeled neural-like cells were cultured in neurogenic medium, and the cells were stained with Calcein-AM and PI for $20 \mathrm{~min}$ at 1,3 , and 6days of induction. Three fields were selected randomly, the number of live cells was counted, and the percentage was calculated.

\section{Determination of $\left[\mathrm{Ca}^{2+}\right] \mathrm{i}$}

The unlabeled and labeled induced cells were loaded with $5 \mu \mathrm{M}$ fluo-3 AM (Invitrogen) for $45 \mathrm{~min}$ at $37^{\circ} \mathrm{C}$. After they were rinsed, the cells were viewed using a Zeiss confocal microscope (400x oil immersion objective; Leica Microsystems, Germany). Furo-3 fluorescence was produced by excitation from a 75-W xenon arc lamp with the appropriate filter sets (excitation $488 \mathrm{~nm}$; emission $526 \mathrm{~nm}$; Sutter Instruments, USA). After baseline images were acquired, the cells were stimulated with $90 \mathrm{mM} \mathrm{KCL}$. Image acquisition continued for $20 \mathrm{~min}$, and the intensities of the intracellular fluorescence were measured at $1600 \mathrm{~s}, 2000 \mathrm{~s}$, and $2400 \mathrm{~s}$ using software. Briefly, regions of interest were defined by drawing an outline around each cell body, and the mean fluorescence was extracted across the time-lapse sequence of the images to obtain fluorescence versus time plots for each cell. Background fluorescence was obtained from a region with no cells for every field examined and subtracted from the mean fluorescence. The mean fluorescence was also corrected by the mean baseline fluorescence, which was determined before cellstimulation. For each treatment condition, 35-40 cells within asingle field of view were analyzed. 
A

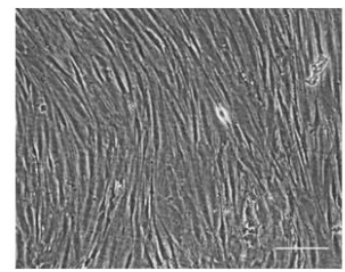

B

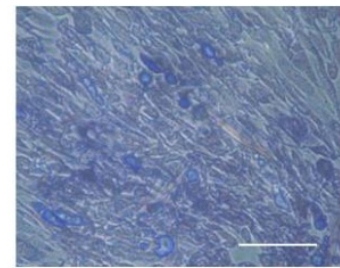

C

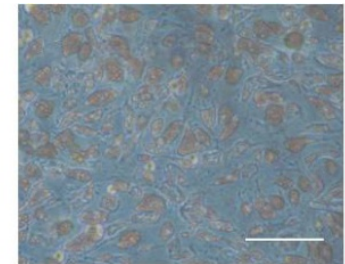

A

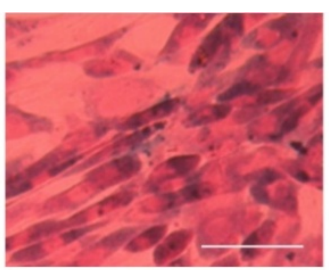

D

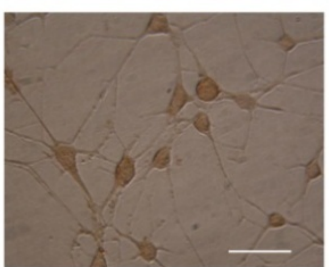

B

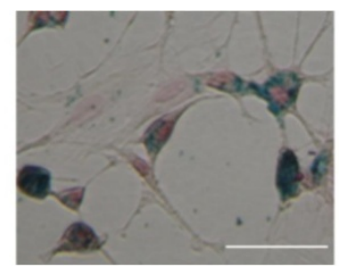

$\mathbf{E}$

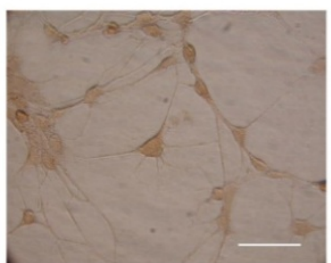

C

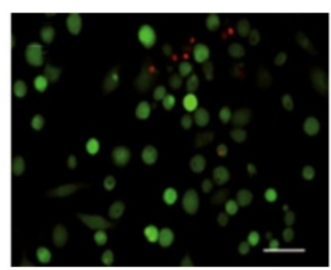

$\mathbf{F}$

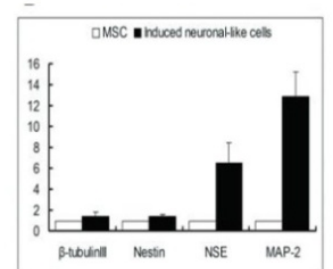

Fig. 1. (A) The morphology of rabbit BM-MSCs. (B)Alkaline phosphatase staining. (C) Oil red O staining of BMMSCs. Scale bar, $100 \mu \mathrm{m}$.

BM-MSCs after exposure to neurogenic medium Scale bar, 50um (F) Passage 3 BM-MSCs were stimu the expression levels of neural-related genes $\beta$-tubulinllI, Nestin, NSE, and MAP-2 were analyzed by qRT-PCR.

\section{Statistical analysis}

Data were expressed as the mean \pm S.D, unless stated otherwise. Prussian blue staining and cell viability were expressed as a percentage of the corresponding unlabeled control cells, and analysis of variance (ANOVA) was performed to test for statistical significance. Comparisons of signal intensity between unlabeled and labeled neural-like cells were performed using the unpaired Student's $t$-test. Statistical analysis was performed using the SPSS 13.0 software for Windows. A P value of $<0.05$ was considered to indicate a statistically significant difference.

\section{RESULTS}

Morphology and phenotypes of cultured BM-MSCs

After isolation from rabbit bone marrow, BM-MSCs were cultured in growth medium. By 14 days of culturing, the cell morphology was characterized as being spindle-shaped under a light microscope, and these BM-MSCs retained an active proliferation capacity in vitro (Fig. 1A). When BM-MSCs were cultured under osteogenic medium for 14 days, these cells could differentiate into osteogenic lineage, as demonstrated by the alkaline phosphatase (ALP) staining (Fig. 1B). In addition, when BM-MSCs were cultured under adipogenic medium for 21 days, these cells could differentiate into adipocytes with lipid droplets stained with Oil red O (Fig. 1C). The FACS analysis (Supplementary Fig. S1) showed that these cultured cells were positive for CD29 and CD44 and negative for CD34 (endothelial cell marker) and CD45 (pan-leukocyte marker); this phenotype is similar to that reported by Dominici M et al. (Kuhn et al., 2010).

\section{BM-MSCs are labeled efficiently by SPIO}

SPIO particles are easily internalized by cells such as macrophages and stem cells, and dextran-coated SPIO are more easily internalized by mesenchymal stem cells (Reddy et al., 2010), so optimal (and often toxic) concentrations are needed for efficient cell labeling. In this study, we chose $25 \mu \mathrm{g} / \mathrm{ml}$ SPIO as the labeling concentration. BM-MSCs were incubated with SPIO for $24 \mathrm{~h}$, and at the end of the stage, SPIO particles were clearly visible inside the cytoplasm. APrussianblueironstaindemonstrated thatthe labeling efficiency of SPIO was nearly 100\% (Fig. 2A).

In vitro viability of induced SPIO-labeled neural-like cells Over $99 \%$ of induced neural-like cells were labeled with SPIO after $24 \mathrm{~h}$ of culture in neurogenic medium (Fig. 2B). CalceinAM/PI staining (Fig. 2C) showed that the average viabilities of induced SPIO-labeled neural-like cells and induced unlabeled neural-like cells were $93.5 \%$ and $94.1 \%$, respectively $(P>0.05)$. They suggested that the SPIO-labeled cells have the same viability as do the unlabeled cells.

Induction of labeled BM-MSCs into neural-like cells SPIO-labeled BM-MSCs were cultured in neurogenic medium. By $24 \mathrm{~h}$, the labeled BM-MSCs showed a neuron-like morphology, which exhibited distinct bipolar or multipolarmorphologies with branched processes. Immunocytochemistry staining revealed that the induced cells were NES- and MAP-2-positive (Figs. $2 \mathrm{D}$ and $2 \mathrm{E}$ ), suggesting that the induced cells expressed the markers of neural lineage cells. The RT-PCR results showed that the expressions of $\beta$-tubulinlll, Nestin, NSE, and MAP-2 (Yan et al., 2013) were up-regulated in induced cells compared with undifferentiated BM-MSCs (Fig. 2F). To evaluate whether these neural-like cells possess function, the inward sodium currents of neural-like cells differentiated from BM-MSCs were evoked by depolarizing voltage commands. Induced 8 days neural-like cells displayed a voltage-dependent sodium current, which showed a feature of fast activation and fast inactivation (Figs. 3B and $3 \mathrm{C}$ ). On the contrary, undifferentiatedBM-MSCs were quiescent, and no inward sodium current was detected (Fig. 3A). 
A
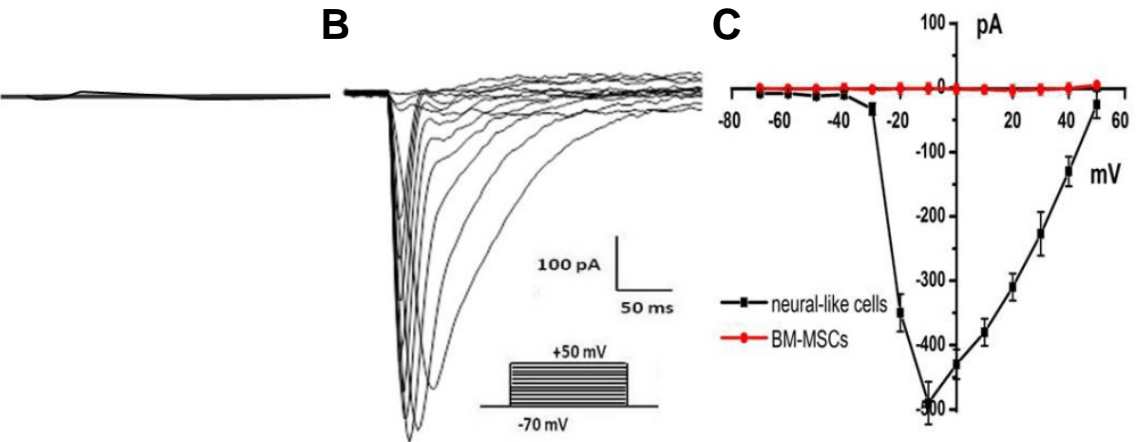

A

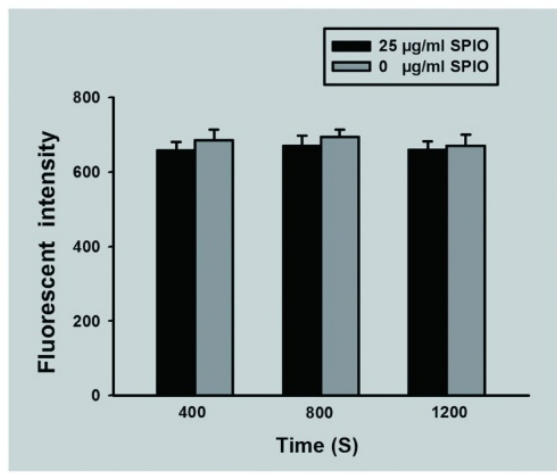

C

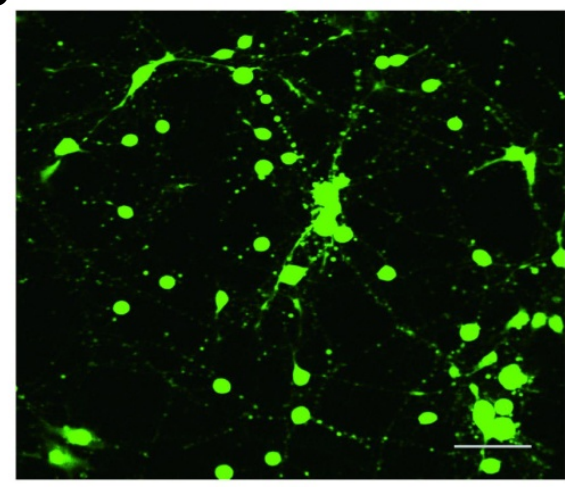

B

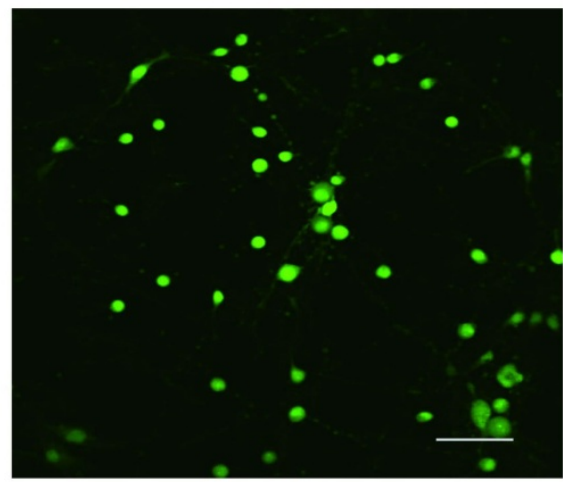

D

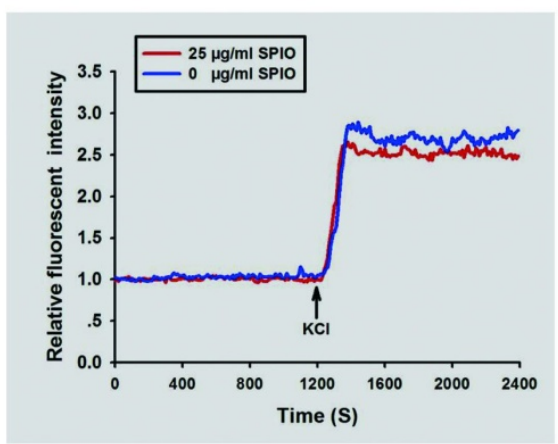

Fig. 3. Electrophysiological analysis for inward sodium current. (A) No inward sodium current was detected in BM-MSCs. (B) Voltagedependent sodium current was detected in BM-MSCs derived neural-like cells. (C) The peak current-voltage relationship was plotted against the voltages.

Fig. 4. The induced SPIO-labeled neural-like cell state. (A) The resting $\left[\mathrm{Ca}^{2+}\right] \mathrm{i}$ concentration tests of induced unlabeled cells and induced SPIO-labeled cells by the fluorescence intensity. (B) The fluorescence staining of induced SPIO-labeled neural-like cells with Flu0-3/AM, stimulation of the cells with $90 \mathrm{mM} \mathrm{KCL}$, Scale bar, 50 $\mu \mathrm{m}$. (C) The fluorescence staining of induced SPIO-labeled neurallike cells showed neural-like cell morphology. Scale bar, $50 \mu \mathrm{m}$. (D) The relative fluorescence intensity of labeled and unlabeled neural-like cells.
In vitro cell state of induced SPIO-labeled neural-like cells The resting $\left[\mathrm{Ca}^{2+}\right] \mathrm{i}$ was not significantly different between induced unlabeled cells and induced SPIO-labeled cells (Fig. 4A). The $\left[\mathrm{Ca}^{2+}\right] \mathrm{i}$ can significantly increase when the extracellular $\left[\mathrm{K}^{+}\right]$ is high in normal cells, so stimulating cells with $\mathrm{KCL}$ can be used to evaluate the cell state. After stimulating cells with $90 \mathrm{mM} \mathrm{KCL}$, the fluorescence intensity of cells was increased significantly (Fig. 4B), and the morphologies of these neural-like cells are shown in Fig. 4C. Stimulation with $90 \mathrm{mM} \mathrm{KCL}$ caused an increase in $\left[\mathrm{Ca}^{2+}\right]$ i that reached a peak up to $260 \%$ (Fig. 4D). The relative fluorescence intensities of labeled and un-labeled neural-like cells were not significantly different (Fig. 4D). These results suggest that induced SPIO-labeled cells and unlabeled cells have the same differentiation ability.

\section{DISCUSSION}

Replacement treatment by neural-like cell transplant is a developing and promising neurological treatment strategy for CNS diseases. In many animal models of CNS diseases, such as spinal cord injury, Parkinson's disease, Alzheimer's disease, and ischemic stroke, cellular replacement therapy using exogenous neuron cells has achieved initial success. For cell transplantation, MR imaging, as a non-invasive method with excellent resolution and without radiation, has been widely used to follow the migration and fate of implanted stem cells (Walczak et al., 2007). Farrell et al. (2008) have demonstrated that long term SPIO labeling of BM-MSCs uninhibited multi-lineage BM-MSCs differentiation (osteogenic, chondrogenic and adipogenic) and could be traced by MRI. Ke et al. (2009) also demonstrated that neural stem cells from BM-MSCs could be labeled with SPIO efficiently. In this study, we show for the first time that BM-MSCs from rabbits labeled in vitro with the superparamagnetic iron oxide (SPIO) contrast agent Reviost can be induced into neural-like cells without affecting the cells' viability and labeling efficiency.

In MR imaging tracking, the contrast agent labeling of stem cells or progenitor cells is a necessary step. Arbab et al. (2003) showed that cells could be labeled with $25-50 \mu \mathrm{g} / \mathrm{ml}$ SPIO efficiently, thus allowing the maintenance of stable functional properties. Walczak et al. (2007) showed the same results, namely 
that labeled cells could be tracked with MRI in vitro for extended periods of time following labeling. Other studies have also demonstrated that the SPIO labeling of BM-MSCs caused no short- or long-term toxic effects (Neriet al., 2008). In this study, we labeled BM-MSCs with $25 \mu \mathrm{g} / \mathrm{ml} \mathrm{SPIO}$ and found that the efficiency of labeling was nearly $100 \%$. These results suggest that BM-MSCs from rabbits could be successfully labeled in vitro using commercially and clinically approved Revoist.

However, our primary goal was to investigate whether SPIOlabeled BM-MSCs retained their differentiation capacity and could differentiate into neural-like cells in vitro. In this study, we showed that a combination of $\beta$-mercaptoethanol and FGF2 (40 $\mathrm{ng} / \mathrm{ml}$ ) may generate neural-like cells from SPIO-labeled BMMSCs. According to previous studies (Woodbury et al., 2000), $\beta$ mercaptoethanol is capable of inducing the differentiation of neural-like cells from BM-MSCs. The induced cells may express neuron-specific enolase (NSE). FGF2 has been reported to benefit neural-lineage development (Murdoch and Roskams, 2013) and has been used extensively in differentiation protocols to promote a neuron cells and glial cells fate (Maricet al., 2007), which may be involved in the start of differentiation from BMMSCs into neuron cells as promote differentiation factor (Pincus et al., 1998). Based on these studies, we acquired the NSEpositive and MAP2-positive neural-like cells from unlabeled and SPIO-labeled BM-MSCs, which showed the morphology of neural-like cells. Most importantly, neural-like cells derived from BMMSCs exhibited electrophysiological characteristics of neurons in vitro. The results suggest that the SPIO labeling of BM-MSCs can differentiate into neural-like cells in vitro. After induction, the SPIO is still observed by Prussian blue staining. However, the induction time is only $24 \mathrm{~h}$, and SPIO particles in the intracellular environment need to be observed for a longer time in future.

With regard to cell viability, some reports (Sun et al., 2012) have suggested that the SPIO labeling of BM-MSCs does not affect cell viability, and our results are consistent with these previous studies. Moreover, the viability of induced SPIO-labeled neural-like cells is as high as that of induced unlabeled cells, and it is very important to use induced SPIO-labeled neural-like cells for cell transplantation and tracking. We also evaluated the induced SPIO-labeled neural-like cells' states by testing the concentration of $\left[\mathrm{Ca}^{2+}\right] \mathrm{i}$ using a confocal microscope. The abnormality of $\left[\mathrm{Ca}^{2+}\right] \mathrm{i}$ is considered to be an important factor for intracellular calcium homeostasis and cell death in neuron cells (Hidalgoand Núñez., 2012). In induced unlabeled and labeled cells, the concentrations of $\left[\mathrm{Ca}^{2+}\right] \mathrm{i}$ are at normal levels. After stimulating the cells with $\mathrm{KCL}$, the $\left[\mathrm{Ca}^{2+}\right]$ i concentrations increased significantly and rapidly, suggesting that the cells were in a good state. The induced SPIO-labeled neural-like cells in a good state might be a potential candidate for seed cells for tissue engineering in nerve regeneration or for replacement therapy in CNS diseases. Moreover, we speculated that the neurallike cells derived from SPIO-labeled BM-MSCs might be in a good state in vivo.

In conclusion, our study showed that BM-MSCs from rabbits labeled with SPIO could be induced into neural-like cells with high cell viability and a good cell state and could be reliably tracked with in vitro MRI for extended periods of time. The results of this research may provide useful evidence for treating nervous system disorders and the future clinical applications of labeling BM-MSCs with SPIO. In addition, the neural-like cells derived from SPIO-labeled BM-MSCs represent a good cell source for regenerative medicine. In summary, the present study demonstrates that BM-MSCs from rabbits labeled with SPIO could be induced into neural-like cells. This strategy does not affect the induced efficiency and cell viability; therefore, it will provide researchers with a simple and straightforward method of magnetically labeling stem cells to track the extent of differentiation in vivo following implantation.

Note: Supplementary information is available on the Molecules and Cells website (uww.molcells.org).

\section{ACKNOWLEDGMENTS}

This study was supported by grants from the National Natural Science Foundation of china (Grant number: 81371628) and Postdoctoral Science Foundation of China (Grant number: 2014T70233, 2013M541206).

\section{REFERENCES}

Arbab, A.S., Bashaw, L.A., Miller, B.R., Jordan, E.K., Lewis, B.K. Kalish, H., and Frank, J.A. (2003). Characterization of biophysical and metabolic properties of cells labeled with superparamagnetic iron oxide nanoparticles and transfection agent for cellular MR imaging. Radiology 229, 838-846.

Daadi, M.M., Hu, S., Klausner, J., Li, Z., Sofilos, M., Sun, G., Wu, J.C., and Steinberg, G.K.(2013). Imaging neural stem cell graftinduced structural repair in stroke. Cell Transplant 22, 881-892.

Eftekharpour, E., Karimi-abdolrezaee, S., and Fehlings, M.G. (2008). Current status of experimental cell replacement approaches to spinal cord injury. Neurosurg. Focus 24, E18.

Farrell, E., Wielopolski, P., Pavljasevic, P., van Tiel, S., Jahr, H., Verhaar, J., Weinans, H., Krestin, G., O'Brien, F.J., et al. (2008). Effects of iron oxide incorporation for long term cell tracking on MSC differentiation in vitro and in vivo. Biochem. Biophys. Res. Commun. 369, 1076-1081.

Gutiérrez-Fernández, M., Rodríguez-Frutos, B., Ramos-Cejudo, J., Teresa Vallejo-Cremades, M., Fuentes, B., Cerdán, S., and DíezTejedor, E. (2013). Effects of intravenous administration of allogenic bone marrow- and adipose tissue-derived mesenchymal stem cells on functional recovery and brain repair markers in experimental ischemic stroke. Stem Cell Res. Ther. 4, 11.

Harris, V.K., Yan, Q.J., Vyshkina, T., Sahabi, S., Liu, X., and Sadiq, S.A. (2012). Clinical and pathological effects of intrathecal injection of mesenchymal stem cell-derived neural progenitors in an experimental model of multiple sclerosis. J. Neurol. Sci. 313, 167-177

Hidalgo, C., and Núñez, M.T. (2007). Calcium, iron and neuronal function. IUBMB Life 59, 280-285.

Hsieh, J.Y., Wang, H.W., Chang, S.J., Liao, K.H., Lee, I.H., Lin, W.S., Wu, C.H., Lin, W.Y., and Cheng, S.M. (2013). Mesenchymal stem cells from human umbilical cord express preferentially secreted factors related to neuroprotection, neurogenesis, and angiogenesis. PLoS One 8, e72604

Jang, S.,Cho, H.H.,Cho, Y.B., Park, J.S., and Jeong, H.S. (2010) Functional neural differentiation of human adipose tissue-derived stem cells using bFGF and forskolin. BMC Cell Biol. 11, 25.

Jing, X.H., Yang, L., Duan, X.J., Xie, B., Chen, W., Li, Z., and Tan, H.B. (2008).In vivo MR imaging tracking of magnetic iron oxide nanoparticle labeled, engineered, autologous bone marrow mesenchymal stem cells following intra-articular injection. Joint Bone Spine 75, 432-438.

Joyce, N., Annett, G., Wirthlin, L., Olson, S., Bauer, G., and Nolta, J.A. (2010). Mesenchymal stem cells for the treatment of neurodegenerative disease. Regen Med. 5, 933-946.

Ke, Y.Q., Hu, C.C., Jiang, X.D., Yang, Z.J., Zhang, H.W., Ji, H.M. Zhou, L.Y., Cai, Y.Q., Qin, L.S., and Xu, R.X. (2009).In vivo magnetic resonance tracking of Feridex-labeled bone marrowderived neural stem cells after autologous transplantation in rhesus monkey. J. Neurosci. Methods 179, 45-50.

Kuhn, N.Z., and Tuan, R.S. (2010). Regulation of stemness and stem cell niche of mesenchymal stem cells: implications in tumorigenesis and metastasis. J. Cell. Physiol. 222, 268-277.

Li, K., Qin, J., Wang, X., Xu, Y., Shen, Z., Lu, X., and Zhang, G. (2013). Magnetic resonance imaging monitoring dual-labeled stem cells for treatment of mouse nerve injury. Cytotherapy 15 , 1275-1285.

Lu, S.S., Liu, S., Zu, Q.Q., Xu, X.Q., Yu, J., Wang, J.W., Zhang, Y., and Shi, H.B. (2013).In vivo MR imaging of intraarterially delivered magnetically labeled mesenchymal stem cells in a canine stroke model.PLoS One 8, e54963.

Maric, D., Fiorio Pla, A., Chang, Y.H., and Barker, J.L. (2007). Selfrenewing and differentiating properties of cortical neural stem 
cells are selectively regulated by basic fibroblast growth factor (FGF) signaling via specific FGF receptors. J. Neurosci. 27, 1836-1852.

Moraes, L., Vasconcelos-dos-Santos, A., Santana, F.C., Godoy, M.A. Rosado-de-Castro, P.H., Jasmin, Azevedo-Pereira, R.L., Cintra, W.M., Gasparetto, E.L., Santiago, M.F., et al. (2012) Neuroprotective effects and magnetic resonance imaging of mesenchymal stem cells labeled with SPION in a rat model of Huntington's disease. Stem Cell Res. 9, 143-155.

Murdoch, B., and Roskams, A.J. (2013). Fibroblast growth factor signaling regulates neurogenesis at multiple stages in the embryonic olfactory epithelium. Stem Cells Dev. 22, 525-537.

Neri, M., Maderna, C., Cavazzin, C., Deidda-Vigoriti, V., Politi, L.S., Scotti, G., Marzola, P., Sbarbati, A., Vescovi, A.L., andGritti, A (2008). Efficient in vitro labeling of human neural precursor cells with superparamagnetic iron oxide particles: relevance for in vivo cell tracking. Stem Cells 26, 505-516.

Peldschus, K., Kaul, M., Nolte-Ernsting, C., Adam, G., and Ittrich, H. (2007). Magnetic resonance imaging of single SPIO labeled mesenchymal stem cells at 3 Tesla. Rofo 179, 473-479.

Pincus, D.W., Keyoung, H.M., Harrison-Restelli, C., Goodman, R.R., Fraser, R.A., Edgar, M., Sakakibara, S., Okano, H., Nedergaard, M., and Goldman, S.A. (1998). Fibroblast growthfactor-2 brain derived neurotrophic factor-associated maturation of new neurons generated from adult human subependymal cells. Ann Neurol. 43, 576-585.

Reddy, A.M., Kwak, B.K., Shim, H.J., Ahn, C., Lee, H.S., Suh, Y.J., and Park, E.S. (2010). In vivo tracking of mesenchymal stem cells labeled with a novel chitosan-coated superparamagnetic iron oxide nanoparticles using 3.0T MRI. J. Korean Med. Sci. 25, 211-219.

Sun, J.H., Zhang, Y.L., Qian, S.P., Yu, X.B., Xie, H.Y., Zhou, L., and Zheng, S.S. (2012). Assessment of biological characteristics of mesenchymal stem cells labeled with superparamagnetic iron ox ide particles in vitro. Mol. Med. Rep. 5, 317-320

Suzuki, H.,Taguchi, T., Tanaka, H., Kataoka, H., Li, Z., Muramatsu, K. Gondo, T., and Kawai, S. (2004). Neurospheres induced from bone marrow stromal cells are multipotent for differentiation into neuron, astrocyte, and oligodendrocyte phenotypes. Biochem. Biophys. Res. Commun. 322, 918-922.

Van Velthoven, C.T., Sheldon, R.A., Kavelaars, A., Derugin, N., Vexler, Z.S., Willemen, H.L., Maas, M., Heijnen, C.J., and Ferriero, D.M. (2013). Mesenchymal stem cell transplantation attenuates brain injury after neonatal stroke. Stroke 44, 1426-1432.

Walczak, P., and Bulte, J.W. (2007). The role of noninvasive cellular imaging in developing cell-based therapies for neurodegenerative disorders. Neurodegener. Dis. 4, 306-313.

Wang, N., Xu, Y., Oin, T., Wang, F.P., Ma, L.L., Luo, X.G., and Zhang, T.C. (2013). Myocardin-related transcription factor-A is a key regulator in retinoic acid-induced neural-like differentiation of adult bone marrow-derived mesenchymal stem cells. Gene 523, 178186.

Walczak, P., Kedziorek, D.A., Gilad, A.A.,Barnett, B.P., and Bulte, J.W (2007). Applicability and limi-tations of MR tracking of neural stem cells with asymmetric cell division and rapid turnover : the case of the shiverer dysmyelinated mousebrain. Magn. Reson. Med. 58, 261-269.

Woodbury, D., Emily, J., Schwarz, E., Prockop, D.J., and Black, I.B. (2000). Adult rat and human bone marrow stromal cells differentiate into neurons. J. Neurosci. Res. 61, 364-370.

Yan, M., Sun, M., Zhou, Y., Wang, W., He, Z., Tang, D., Lu, S., Wang X., Li, S., Wang, W., et al. (2013). Conversion of human umbilical cord mesenchymal stem cells in Wharton's jelly to dopamine neurons mediated by the $\mathrm{Lm \times 1a}$ and neurturinin vitro: potential therapeutic application for Parkinson's disease in a rhesus monkey model. PLoS One 8, e64000. 